\title{
Descubriendo claves para explicar las políticas sociales dentro del Estado social y democrático de derecho
}

\author{
Discovering keys to explain social policies within the social \\ and democratic rule-of-law sate \\ Ma José LACAlZADA DE MATEO \\ Universidad de Zaragoza, España \\ mjlacalzada@unizar.es
}

Recibido: $16 / 05 / 2015$

Revisado: 01/06/2015

Aceptado: 25/11/2015

Disponible on line: 20/01/2016

\section{Resumen}

Existe un imaginario colectivo sobre políticas sociales con el que los profesionales universitarios se expresan y comprenden. Sin embargo, a los estudiantes les lleva tiempo llegar a construir esos conocimientos.

Este artículo no es de reflexión científica para especialistas sino una propuesta de actividad pedagógica, aludiendo a un material de apoyo, cuya lectura puede involucrar tanto al profesorado como al alumnado. La intención es compartir ideas y una dinámica para facilitar el aprendizaje de las políticas sociales.

La elaboración de un breve diccionario de términos significativos construidos en grupo. junto al trabajo de mayéutica que cabe al profesor, permiten descubrir claves para entender el sentido de las políticas sociales dentro de los valores de fondo propios de un Estado social y democrático de derecho, tal y como recoge la Constitución española de 1978.

Esta propuesta tiene un sentido integral orientada en tres dimensiones: el Estado y sus posibles agentes de bienestar: empresa, mercado, iglesia, sociedad civil. Las actitudes con las que se promueve la acción social en sentido universal e inclusivo, rompiendo radicalmente con el sentido benéfico-asistencial propio de otros sistemas. La dignidad humana como principio y fin de la intervención, base de otros conceptos como: derechos humanos, sociales, laborales y políticos.

Palabras clave: Política social, Trabajo Social, Estado de bienestar mixto, Estado social y democrático de derecho, derechos humanos.

\begin{abstract}
There is a collective worldview on social policies that is expressed and understood by university professionals. However, it takes students time to construct this knowledge. Here, we provide fundamental ideas and a dynamic to facilitate learning of social policies. The preparation of a brief dictionary of significant terms is to be constructed as a group, alongside the maieutic work to be carried out by the teacher. The goal is to discover keys to understand the meaning of social policies and the underlying values that sustain a social and democratic rule-of-law state such as the one proposed in the Spanish Constitution of 1978. Attention is focused on the structure of the mixed welfare state. This is an integral proposal and comprises three dimensions. First, it considers the state and its possible welfare agents: business, market, the Church and civil society. The attitudes with which universal and inclusive social action is promoted, breaking radically with the aid-based meaning contained in other systems, are then addressed. Finally, we examine human dignity as a principle and aim of intervention, a basis for understanding other concepts such as human, social, labour and political rights. It is to be hoped that these pages prove useful for both teaching staff and students.
\end{abstract}

Keywords: Social policy, Social Work, welfare state, social and democratic rule-of-law state, human rights.

Referencia normalizada: Lacalzada de Mateo, M J. (2016): «Descubriendo claves para explicar las políticas sociales dentro del Estado social y democrático de derecho». Cuadernos de Trabajo Social, 29(1): 95-108.

Sumario: 1. La política social en la formación de los trabajadores sociales. 2. Una manera de ayudar a conocer, comprender y descubrir conceptos fundamentales. 3. Una propuesta sobre conceptos para descubrir y para comprender. 4. Referencias bibliográficas. 


\section{La política social en la formación de los trabajadores sociales}

Contemplar la política social en la formación académica de los futuros trabajadores sociales, $y$ además dentro de una materia donde pueden desarrollarse varias asignaturas, es todo un acierto. No solo complementa la formación de estos profesionales de la intervención, sino que les sitúa en el núcleo del sistema. Introduce en una dimensión universitaria más amplia. Esta nueva perspectiva puede subrayar una entidad profesional que capacita no solo para planificar, intervenir y gestionar, sino también para acceder a posibles niveles de participación en la toma de decisiones, en el diseño de programas y, por lo tanto, en la creación de nuevas políticas sociales. Todo ello confiere a la profesión un carácter plenamente ensamblado dentro del arte del diseño y gestión de la polis, y, en cierto modo, del gobierno de la misma.

A través de las políticas sociales, entramos en la filosofía política y jurídica donde suceden las intervenciones propiamente sociales, entendiendo cómo ciertas actividades pueden contribuir a la integración social o, por el contrario, ahondan factores de vulnerabilidad y empujan hacia la exclusión. Esta perspectiva integral posibilita que la intervención social sea un instrumento de cambio, sirviendo para la creación y expansión de recursos y para el bienestar de las personas. Y, podemos preguntarnos: ¿cómo hacer para que los conocimientos sobre políticas e intervenciones sociales, que se van adquiriendo a lo largo de los cuatro años, no queden en un haz de informaciones e ideas aisladas, sin una articulación sistémica de fondo?

La estructura del Estado es el referente que debe quedar construido de manera simbólica. Es aquí donde se forman las relaciones de poder y la ciudadanía accede a los medios de vida. Es necesario, por lo tanto, imaginar los valores que puede promover, proteger y garantizar el Estado, aprendiendo a especificar sus líneas de actuación: jurídicas e institucionales, así como los diferentes agentes que deberán complementarlo. Las empresas, generadoras de empleo y también proveedoras de seguros y servicios, trazan esas líneas por donde va tomando forma la arquitectura de Estado mixto que tenemos y, por lo tanto, la concepción que deberán adquirir los estudiantes.

Estado y sociedad civil forman un par indisoluble dentro de los sistemas democráticos. Más aún, la permeabilidad entre ambos es garantía de que la soberanía, una vez delegada en las urnas, no quede secuestrada por una élite que gobierne en su propio beneficio y en el de sus clientes.

$\mathrm{Y}$ es que, efectivamente, el modo de producir económico-social marca y pauta el acceso al mundo del trabajo, a su remuneración, a la redistribución de beneficios y salarios, a las inversiones o el consumo interior que marcan el nivel de civilización de un país. El desarrollo económico, con la cohesión social interior, han sido fundamento de diferentes Estados de bienestar, a partir de 1945. Los intercambios con el exterior, que completaban las identidades y el protagonismo internacional de cada uno de los Estados, han llegado a adquirir dimensiones tales en mercados desregularizados que la soberanía de los países hoy queda en retroceso frente a grandes marcas, lobbies trasnacionales que mueven riquezas y capitales, en un sentido exclusivamente materialista.

La brecha social, resultado de la última crisis, está revelando unas élites que acumulan y derivan capitales en circuitos exteriores que ya no vuelven a los países de origen —o por lo menos de manera inmediata - dejando en condiciones de precariedad, los recursos a los que la ciudadanía debería acceder. Una vez salvado el sostenimiento financiero y la circulación de las grandes fortunas, se habla de la salida de la crisis en España. Efectivamente, de la manera que muchos temieron y otros promovieron: rendidos a los intereses de las multinacionales, con trabajos precarios, y quedando en segundo plano las inversiones y redistribución interior de las riquezas, el bienestar de la ciudadanía.

A pesar de los pesares, el entramado para explicar nuestro referente de Estado sigue siendo el mismo, simplemente viene recogiendo una trayectoria histórica por el camino. La Constitución española de 1978 es la piedra angular desde la que está construido el Estado de bienestar mixto que tenemos, y la que sostiene los valores propios de un Estado social y democrático de Derecho. Y aquí ensambla consecuentemente la gestación y aplicación práctica de las diferentes políticas sociales y el papel del trabajador social dentro de ellas.

Cuestiones que pueden parecer evidentes, a quienes estamos familiarizados con el lenguaje de las políticas sociales, aparecen, sin embargo, dentro de una espesa nebulosa para la mayor par- 
te de nuestros estudiantes. Es natural que así sea y necesario, por lo tanto, ayudarles a estructurar la cabeza. Si el andamiaje sobre la entidad del Estado, sus agentes de bienestar complementarios y el fluir de las diferentes políticas sociales queda bien puesto, ya desde el principio, podrá entrarse más a fondo y con mayor facilidad en asignaturas que vendrán después, como: sistemas de bienestar, organización de los Servicios Sociales o programas y prestaciones de los Servicios Sociales, y especialmente, en las políticas sociales en España.

¿Cómo situar de una manera efectiva y activa al alumnado ante las políticas sociales desde el primer curso?

\section{Una manera de ayudar a conocer, com- prender $y$ descubrir conceptos fundamentales} Si tomamos en consideración promover la actitud activa del estudiante en la búsqueda del conocimiento, no podemos dejar de lado el trabajo de mayéutica que cabe al profesor. Esto no es nuevo. Forma parte del método socrático, y fue promovido en su tiempo por algunos intelectuales de la Institución Libre de Enseñanza, dispuestos a despertar la autonomía de las conciencias y conectar la escuela con la vida. Pese a las recientes llamadas al aprendizaje activo, concepto que debería ir unido a consciente, los resultados suelen acabar vinculados más a las destrezas que a la profundidad en la búsqueda y la interpretación de los mismos. También es verdad - ¿para qué engañarse? - que es el reflejo de la sociedad de imagen en la que estamos inmersos. Pretender adquirir conocimiento a contracorriente del tiempo es un absurdo, aunque siempre acabe sabiéndose algo. Conocer es más profundo que identificar, saber, tener ideas, e incluso entender. Aunque, isuerte, y démonos por satisfechos! si alcanzamos estos niveles en nuestras actividades académicas.

Elaborar un pequeño diccionario de términos o conceptos, como queramos llamarlo, es un instrumento para asentar ideas y descubrir ciertas claves para entender las política sociales. Las palabras, refiriéndose a las estructuras o a las intervenciones políticas, tienen su sentido y matiz correspondiente que tenemos la ocasión de ayudar a entender. Estaremos trabajando al mismo tiempo con la capacidad de comprensión y la de síntesis, para demostrar que se sabe bien qué es lo que se está diciendo. Seguramente se sabrá y se indagará más que lo expresado en ese breve espacio permitido; es ese el valor añadido.

La dinámica expuesta a continuación ha sido experimentada durante cinco cursos, en la asignatura de «Introducción a la Política Social», impartida en el primer cuatrimestre del primer curso de Trabajo Social. El objetivo ha sido a lo largo de estos años tratar de que se entiendan conceptos, fundamentos, ideas, obteniendo - de paso - una estructura de cabeza, que tan dificultosamente puede llegar a transmitirse $\mathrm{y}$, menos aún, a descubrir de manera aislada. La presión de las restantes asignaturas y la limitación del horario caen inexorablemente. El tiempo durante este cuatrimestre corre más deprisa y la atención está más dispersa y desorientada que en los posteriores; tienen suerte las universidades donde se imparte en cuatrimestres más adelante.

Los créditos $\mathrm{T} 6$ son actividades presenciales bajo tutela del profesor, que pueden destinarse a elaborar un trabajo, para fomentar la autonomía en el aprendizaje y el trabajo posterior. Por lo menos así está recogido dentro de los planes de estudio. Es este un espacio ideal, cuando hay motivación por la docencia y el grupo lo permite, para encontrarse directamente con el estudiante y llegar a un intercambio más personalizado. Planificado el tiempo, puede lograrse un ritmo de 5 y hasta 6 encuentros con cada uno de los grupitos cada 15 días. Si se hace con agilidad se puede llegar a gestionar tres o cuatro grupitos al mismo tiempo. Eso da ocasión para aprender unos de otros comparando los resultados. La experiencia en que se apoya este artículo ha venido siendo, en cada uno de los cursos, de unos 60 alumnos distribuidos en grupitos de 5 personas.

El día de la primera reunión se explica que se deben aportar ideas claras, que pueden tener origen en lo descubierto o escuchado en las clases teóricas o prácticas. Eso es lo deseable: avanzar a medida que se va desarrollando la asignatura. La experiencia demuestra que las ideas previamente expuestas y escuchadas son las que mejor facilitan el avance del trabajo, ya que aportan un primer enfoque y evitan la dispersión de energías o búsquedas que pueden no conducir al objetivo deseado. El alumno se sitúa como co-creador de su propio aprendizaje. Cada reunión sirve para revisar él o los términos trabajados dentro del grupo y proponer los que se deben traer para la reunión siguiente. A ella se vuelve con la tarea consensuada y las nuevas definiciones. La expo- 
sición y debate de ciertos términos se presta también a hacerse en las clases teóricas y o en las clases prácticas. La redacción y entrega final puede quedar abierta hasta completar los términos elegidos.

¿Es suficiente con las ideas recogidas en las clases? Naturalmente que no. Es importante aprender a entrar por otras fuentes del conocimiento. ¿Cuáles? No está de más recordar que hay unos manuales recomendados y una bibliografía con la que familiarizarse. Además - esto no hay que recordarlo - disponemos de un atrayente espacio virtual al que cualquiera puede acceder. Lo que sistemáticamente deberemos decir es algo así como: ¡en internet está todo y también nada, si no tenéis criterio para buscarlo! Los estudiantes tienden a venir, al principio, con párrafos copiados con poco nivel de consciencia o manifiestamente difusos y hasta contradictorios. Es natural, la destreza de pasar frases a medio entender se trae del bachillerato y - desgraciadamente - tiende a desarrollarse dentro de la Universidad. También es frecuente tratar de encontrar definiciones ya hechas. Esto aporta muy poco al conocimiento. ¿Cómo iniciar el giro de perspectiva?

La pregunta es elemental: ¿Qué quieres decir?, corre paralela a: ¿De dónde ha salido esta idea? La respuesta, en la práctica totalidad de los casos, es: ¡de internet! Las preguntas continúan. ¿De qué página? Esto da pie a continuar con preguntas como: ¿Quién es el autor? ¿Qué institución está detrás ¿Bajo qué punto de vista está escrita? ¿Se trata de un texto con perspectiva jurídica, económica, política, sociológica, etc.? A veces, se ha dado con autores, instituciones o revistas que merece la pena valorar y reforzar en positivo el hallazgo. También, si llega el caso, es la oportunidad para rechazar, exponiendo por qué razón no debe servir e indicar, entonces, otra fuente más aconsejable. Al profesor compete centrar ideas. Sobre todo es necesario saber qué es lo que se está diciendo, y sugerir que no se debe escribir aquello que no se entiende.

Lo deseable es animar a estar consciente, dentro de las clases y a familiarizarse con manuales recomendados, algún libro, artículo o páginas seguras en el espacio virtual. Y así se pueden comenzar a conocer autores e instituciones que merecen servir de referencia y, naturalmen- te, a ser citados correctamente. También pueden sugerirse, si se presenta la oportunidad, ciertos artículos de periódico o tweets que estén circulando.

Una pregunta insoslayable: ¿Cuántas páginas debe ocupar cada término? «Las que necesites para expresar bien la idea, para dejar claro el concepto», tiende a ser mi respuesta. No cuenta la cantidad sino la calidad. Eso sí, breve, expresivo y directo. Entre una y dos páginas, suele ser suficiente. Redactar más desvía del objetivo propuesto que es centrar ideas. Una vez que queda sucinto el término, puede prestarse a indicar alguna bibliografía, algún artículo o recurso en que se ha apoyado; y ¡ojito! no se debe poner aquello de apuntes de clase, jeso ya va implícito!

Esta misma actitud y trabajo académico puede plantearse mediante un Foro o elaborando una wikipedia a través del Anillo Digital Docen$t^{1}$. Seguramente si este artículo hubiera sido enfocado así, desde el principio resultaría más atractivo y, visto así, por las formas sería considerado novedoso y de impacto metodológico. Deliberadamente he optado por lo menos vistoso. Si sabemos deslindar hasta dónde llega la herramienta de trabajo y hasta dónde la cabeza que la maneja, podemos poner cada cosa en su lugar. Aquí el protagonismo lo tiene la formación de las cabezas, la herramienta es secundaria, salvo que ayude para la motivación. Y que cada cual utilice la que crea más conveniente.

El trato directo personal, que tanto engrandece la labor docente, no figura entre las nuevas tecnologías. Sin embargo, no significa que contribuya en menor medida a la formación ni que no proporcione buenos recursos para la comunicación, la trasmisión e intercambio de conocimientos. La ocasión de mirarse, de conectar en ciertos niveles instintivos, y debatir, es toda una experiencia formativa e interactiva. Es así, como se va construyendo el conocimiento. Las aplicaciones informáticas carecen de alma, o por lo menos, tienen menos registros humanos.

\section{Una propuesta sobre conceptos para des- cubrir y para comprender}

¿Cómo fundamentar las políticas sociales a partir de ideas básicas que abran la mente hacia una panorámica integral? Dicho de otro modo: ¿Qué conceptos deberían quedar asentados ya desde el

\footnotetext{
${ }^{1}$ Conocido también como Campus virtual.
} 
primer curso? A continuación tenemos una propuesta piloto con términos donde puede quedar centrada una asignatura introductoria a la Política social. Es útil agruparlos a fin de que no parezcan dispersos, inconexos, elegidos al azar. Tenemos tres ejes bien expresivos que conforman una identidad de conjunto: la estructura y relaciones dentro del Estado; el sentido de la acciónintervención; los valores que subyacen.

\section{La estructura del Estado liberal parlamenta- rio en su evolución:}

Los tres poderes del Estado: legislativo, ejecutivo, judicial.

Soberanía nacional-Ciudadanía.

Estado liberal-intervencionista-de bienestarde bienestar mixto.

Pleno empleo-seguros y servicios sociales.

Modelos o referentes de estados de bienestar.

Estado social y democrático de derecho.

Estado-Empresa/Mercado-Iglesia-Sociedad civil.

Tercer sector-voluntariado-bienes relacionales.

\section{EI estilo de la protección a encontrar en la so- ciedad:}

Necesidad individual-necesidad social.

Universalidad de las políticas sociales.

Público-privado.

Externalizar-privatizar.

Beneficencia-asistencia-derechos sociales de la ciudadanía.

Inclusión-exclusión social-cohesión social.

\section{Lo relativo a la identidad de las personas:}

Dignidad humana.

Diversidad humana (discapacidad, género, raza, cultura, religión, etc.).

Derechos humanos-sociales-laboralespolíticos.

Presentar una plantilla completa, al comenzar el curso, ayuda a intuir la globalidad. Aunque no se trabajen todos los términos, siempre queda la advertencia de que son significativos. Tampoco está cerrado, pueden incluirse conceptos no contemplados inicialmente, pero que se haya mostrado curiosidad o permeabilidad o que, por su actualidad, sea conveniente incidir. No se trata tanto de abarcar muchos términos como de suscitar curiosidad, motivación para desentrañar la complejidad, y satisfacción una vez conseguido. Importa la dinámica creada.
Veamos algunas pautas que están dando resultado.

\section{a) La estructuración de los Estados en su tra- yectoria histórica}

Existe un estilo diferenciador de base entre el mundo anglosajón y la matriz continental europea; puede ser un idóneo punto de partida para centrar a nuestros estudiantes. Ashford (1989), supo verlo muy claro cuando en su libro sobre los Estados de bienestar hizo notar que en Francia las autoridades municipales, tras la revolución, mantuvieron proximidad para dar respuesta a los problemas del pueblo, cosa que en Inglaterra no. Recordemos que el Libro Blanco para la reforma del Plan de estudios de Trabajo Social, entre las competencias a adquirir, pide situarse en el conocimiento y comprensión de los orígenes de los Estados de bienestar.

Neoliberalismo y socialdemocracia, dos ejes paradigmáticos, son términos a tener en cuenta. Una simplificación pedagógica indica que el primero confía la producción de los recursos y el bienestar social a la libertad y el valor del trabajo individual y la segunda pone en manos del Estado una función redistributiva. El primero tiene su origen en la mentalidad anglosajona, la segunda en movimientos de solidaridad dentro del continente europeo. Es así de simple, después pueden venir las matizaciones, a medida que se entra en preguntas y explicaciones consiguientes.

Si tomamos el referente de Inglaterra llegaremos a la responsabilidad del individuo, pero no tanto a la del Estado, que le bastará con promover el juego de las libertades y atender de manera residual, más por cuestión de orden público que de sentido humanitario; este último se deja en manos de iniciativas filantrópicas. La revolución inglesa, que se remonta al siglo XVII, sirvió para consolidar los poderes de las nuevas familias emprendedoras frente a otras estancadas en los privilegios de nobleza. Aquella burguesía de negocios pedía su puesto para crear riqueza y repartírsela. La Ilustración en Inglaterra, no en vano, tiene unos de sus mejores exponentes en Locke que explicitó el fundamento del sistema político en tres axiomas significativos: La propiedad privada es un derecho natural. El contrato social se realiza para preservar la propiedad. La propiedad no es asunto del Estado - no forma parte de su naturaleza - y debe abstenerse por todos medios de intervenir. 
Vistas así las cosas, tenemos un primer retrato robot de Estado liberal y además parlamentario. Es preciso, a fin de asentar ideas básicas, llegar hasta la caricatura. Digamos por ejemplo: «El Estado liberal solo debe respetar las libertades y el derecho de propiedad»». Esta idea troncal tiene más explicaciones, como: los derechos sociales no son su cometido, si interviene perjudica al desarrollo de la economía y es esperable que sean las leyes del mercado las que con el tiempo contribuyan al equilibrio ¿De quién? La mentalidad dominante en aquellos primeros años justificaba la inhibición de los poderes públicos. Las libertades estaban envueltas todavía de una pátina progresista frente a los tiempos en que habían dominado los privilegios estamentales. Y, sin embargo, las libertades sin reglas acaban siendo privilegios para quienes se asientan mejor en los nuevos poderes.

El otro punto de referencia, ya hemos dicho, está en el continente europeo, desde el que podremos identificar el paso del primer Estado liberal hacia el que cargaremos de contenido como «intervencionista».

La Revolución Francesa, producida justo cien años después, asentó el Estado liberal parlamentario bajo otra filosofía política. ¿Cuál? Los representantes políticos no deben responder tan solo a los intereses de esas clases económicas en ascenso que quieren maximizar el capital. Aquella burguesía emprendedora en su lucha contra los privilegiados supo atraer a su causa al campesinado y demás capas populares, hombres y mujeres protagonizaron jornadas inolvidables. La cuestión de la soberanía nacional fue troncal. Sabido es que una vez asentadas las primeras élites en el poder no tuvieron prisa en extender los beneficios ni ampliar la participación. El germen, sin embargo, estaba puesto y pudo alentar sucesivas revoluciones en 1830, 1848 y 1868 , reclamando los derechos para las clases populares por un implícito sentido de justicia social.

Una dificultad muy frecuente suele ser distinguir el Estado intervencionista del Estado de bienestar social. ¿Por qué? Al buscar por la red resultan equivalentes, si no se discurre demasiado. Y a poquito que se piense, siempre y de alguna manera existe la intervención. ¿Intervenir en qué sentido? ¿Dónde ponemos los límites para entender este primer puente hacia el Estado de bienestar? Esas son las preguntas que deberemos responder. Es importante, en este caso, seguir dentro de la perspectiva histórica.
La Alemania de Bismark fue el primer paso hacia el intervencionismo del Estado. Las leyes recogieron la obligación de cotizar (a empresarios y trabajadores) y así garantizar unos seguros sociales. Entre 1881 y 1885 tenemos el núcleo inicial, la garantía de unos seguros ante la enfermedad, viudedad, orfandad y vejez. Este paso, por mínimo que fuese, supuso la demostración empírica, frente a las resistencias puristas del liberalismo, que no se entorpecía la economía, mediante planificaciones y medidas redistribuidoras por parte de los poderes políticos. Todo lo contrario: comerciantes, industriales y banqueros mejoraron sus expectativas.

No está de más recordar que la Ilustración en Alemania tiene un sustrato de pensamiento en el que el Estado representa el desarrollo superior de la personalidad de las sociedades, unido a la esfera racionalizadora del derecho. Tras la Guerra, a partir de 1919 veremos apuntar ya, en la Constitución de la República de Weimar, todo un embrión de seguros, servicios y actitudes políticas que recogerán posteriormente los Estados del bienestar. Aquí marcamos la divisoria. El Estado intervencionista quedará definido desde su primera experiencia en Alemania que pone los principios a la seguridad social y comienza a reconocer en su marco jurídico el acceso a ciertos derechos calificables como sociales.

El Estado de bienestar es la respuesta de políticos y economistas liberales ante la crisis de 1929. Es importante dejar esta idea bien centrada. La salida a la crisis fue viable, fomentando la circulación monetaria dentro de cada unos de los Estados. Beveridge, asesorando al parlamento británico; Keynes, propiciando medidas como economista la política de Roosvelt en Estados Unidos, resultan tres referentes sobre los que llevar la atención. El crecimiento de la economía en el interior de los Estados fue el signo del progreso por entonces. Producción-trabajo-consumo interior se retroalimentaban en un equilibrio que a todos beneficiaba. A medida que subía la entidad de consumidor bajaba la rentabilidad de explotar al obrero. Eran dos caras de una misma persona, produciendo y consumiendo, ya ubicada dentro de las políticas públicas.

Resulta toda una evidencia histórica que cuando los intelectuales como los socialistas fabianos plantearon ciertos fundamentos, apelando a ideas de justicia social, el sistema dominante los ninguneó desplazándolos a los terrenos de 
la utopía. Aún no se había demostrado la rentabilidad que los ricos y poderosos podían obtener. El informe alternativo de la minoría, (Minority Report) que en 1905, entre otros, prepararon Beatrice Potter y Sydney Webb frente al informe oficial para reformar la Ley de Pobres de 1834, fue un hito significativo. Ramos Gorostiza tiene un artículo que llega fácilmente a estudiantes. La sentencia estaba clara: más que continuar reformando había que finalizar con Poor Law. Y las razones también: Es un parche que no activa los medios necesarios y efectivos de prevención para salir de los círculos envolventes de miseria. $\mathrm{Al}$ mismo tiempo se propusieron medidas racionalizadoras como establecer:

- Oficinas de empleo para lograr un uso eficiente y coordinado de los recursos laborales.

- Un estándar mínimo de vida, salud, educación, vivienda, ingreso y ocio, para ambos sexos.

- Un sistema de pensiones de ancianidad y la provisión presupuestaria sanitaria administrada por las autoridades públicas y un programa contra el desempleo.

Estas tres dimensiones señaladas aportan ideas sólidas a nuestro diccionario. Aquel informe era una especie de «libro blanco» sobre un sistema de seguridad social de la cuna a la tumba, sería calificado por Lord Beveridge como la principal contribución de los Webb al pensamiento social (Ramos Gorostiza, s/f).

Así, para definir de manera clara y limpia el Estado de bienestar, hemos de entrar por la fórmula de Beveridge: pleno empleo en sociedades libres, unido al conjunto de seguros y servicios sociales. El eje queda bien fijado así. Entrar en el concepto de pleno empleo es un buen ejercicio. El propio Beveridge (1988) ayuda bien a centrar la idea en cuatro páginas de su extenso y detallado informe explicando el significado del pleno empleo y el propósito del mismo (pp. 3841). Hagamos notar que debe quedar un margen de puestos vacantes a beneficio de quien busca trabajo y no de quien lo oferta, como pérfidamente está sucediendo en nuestros días.

Fue, al materializarse los Estados de bienestar, cuando tomó madurez el sentido de la política social, entendido como responsabilidad de los poderes públicos. La educación, la sanidad, la vivienda fueron ya catalogadas como políticas pú- blicas extensivas al conjunto de la ciudadanía y garantizando condiciones de equidad. Así mismo las pensiones, prestaciones por desempleo $\mathrm{u}$ otros conceptos, y las rentas mínimas de inserción vienen dando forma a la seguridad y protección social.

La crisis del petróleo (1975) fue revelando en esta década la existencia de entidades por encima de la soberanía de los Estados que introducían nuevas variables. Los defensores del neoliberalismo difundieron la consigna de que el gasto social fuese insostenible - no faltaban datos para demostrarlo - obviando la dimensión que podía tomar con una buena gestión que lo entendiera como inversión social. Sin embargo, parecía irrenunciable el nivel de vida, cobertura y seguridad creado como prueba de prosperidad. La salida fue la fórmula de Estado de bienestar mixto. Este lleva consigo complementar la responsabilidad central del Estado mediante las iniciativas privadas, con ánimo de lucro y sin él.

Entender la responsabilidad social del Estado, como reflejo delegado de los intereses de la ciudadanía, es fundamental. Las libertades pueden quedar garantizadas y extenderse a todas las clases sociales: desde quienes viven entre facilidades y recursos hasta quienes parten de las carencias más absolutas. Es decir, políticas públicas que afiancen las libertades propiciando la equidad en las oportunidades y compensando los estragos que pueda provocar la iniciativa libre abandonada a sí misma.

Desde los inicios de la modernidad, definir la soberanía de la nación, como delegada en los representantes políticos, ha venido confiriendo legitimidad a los gobiernos. Una vez destruido el ordenamiento político del Antiguo Régimen, el poder ya no podrá escudarse en presuntas voluntades divinas ni en privilegios de sangre. El plano de equilibrio lo encontramos a medida que una parte de nuestra soberanía queda manejada por los gobiernos representativos y la otra ejercida por nosotros mismos por medio de la sociedad civil. Así pues, tirando de esta idea, será posible esa progresiva construcción de derechos que van dando forma al concepto actual de ciudadanía, dentro de la participación democrática.

Reconocemos a T.H. Marshall, en su conferencia sobre Ciudadanía y clase social (Marshall y Bottomore, 1988), como punto de referencia y voz de autoridad para defender un sentido evolutivo: primero, en el reconocimiento de los dere- 
chos civiles (junto a las libertades); después de los políticos y más tarde de los sociales que llegan a fundamentar los Estados de bienestar (pp. 22-31). La línea abierta por la Filosofía del Derecho viene refiriéndose a derechos de primera generación como los civiles y políticos, unidos a las libertades individuales, a lo largo del siglo XIX, y los de segunda generación como los económicos, sociales y culturales, que contemplan la dimensión social, desarrollados durante el siglo XX. Estamos ante una tercera generación, en la que nuestros sistemas de bienestar deberán tener en cuenta los derechos medioambientales y de las generaciones futuras (Martínez de Pisón, 1998, pp. 69-74 y 85-94).

Los diferentes modelos o regímenes de bienestar son también referentes que conviene clarificar. El encuadre se hace bien recordando los polos extremos hacia el neoliberalismo o hacia la socialdemocracia. Sobra añadir que así explicamos tendencias, la realidad es siempre compleja y cambiante. Es indispensable Richard M. Titmuss (1981) como fundamento de este cometido. La descripción de tres modelos en breves párrafos (residual, logro personal-resultado laboral e institucional-redistributivo) ha sido el punto de arranque para muchos politólogos y sociólogos que ha venido después y el puerto seguro para que los estudiantes comiencen a situarse (pp. 38-39).

Este núcleo de Titmuss deberá complementarse con Esping-Andersen (1993) que, como sabemos, sitúa el juego con el Mercado. Entra así un concepto nuevo, y un descubrimiento que ayuda a la gimnasia mental, entendiendo que desmercantilizar es asumir el Estado y mercantilizar responsabilizarse directamente el mercado (pp. 47-49). Otras páginas para detener la atención las proporciona Joseph Picó (1996) que centra y ayuda a comprender a diferentes autores (pp. 44-47 y 48-55). Debe descubrirse también que España muestra un modelo propio de los países del sur. Tienen en común: una industrialización tardía, el peso de la Iglesia católica y el sentido de la familia. Ya en los años noventa se perfiló este nuevo referente (Ferrera, 1995, pp. 103-109). Esther Raya (2002) aporta un cuadro expresivo para descubrir junto al alumnado (p. 91). Los individuos y las familias, por cierto, deberán ser comprendidos como sujeto de derechos y no como reparadores de los fallos del Estado y el Mercado.
En definitiva, el esquema que ha de quedar es la interacción del poder público del Estado fijando deberes, derechos y libertades mediante el legislativo y poniendo medios a partir de las Administraciones públicas; el Mercado con su lógica empresarial; y las organizaciones a través de la sociedad civil sin ánimo de lucro. Una pregunta interesante para definirlas e indagar: ¿en qué medida pueden ser agentes proveedores de bienestar? Y ¿respecto a qué referente? Efectivamente, el Estado social y democrático de derecho:

La empresa y el mercado ¿pueden serlo? Dependerá de sus medios y resultados. Si buscan explícitamente el máximo beneficio según las leyes del mercado y conforme a criterios materialistas individualistas, no podemos tenerla por tal y menos en un Estado que alberga el calificativo de social. Proveer bienestar ¿sólo para la minoría que pueda comprarlo? eso es otra cosa, dentro de las políticas públicas. El concepto de empresa, desengañémonos, inicialmente ha ido vinculado a la idea de negocio y se ha desarrollado a medida que quienes las dirigen obtienen ganancias que no pocas veces son a costa del reparto equitativo y del medioambiente.

Es verdad que si una empresa proporciona salarios justos, seguros adecuados, etc. ¿Entraría en el calificativo de agente proveedor de bienestar? Los más conformistas tal vez acepten una definición así. Otros pueden objetar que con tal comportamiento no va más allá de lo exigible por la ley. Y, desde luego, así queda mejor centrada la idea: la empresa adecuándose a los derechos laborales contemplados en la legislación simplemente cumple con su obligación. Otra cosa es que tal empresa proporcione otros beneficios sociales más allá de la entidad misma de trabajador, contribuyendo al bienestar familiar y social: servicio de guardería, entrar en políticas inclusivas y de conciliación familiar, etc. La responsabilidad social corporativa y las empresas de economía social, ha venido siendo un interesante concepto en los últimos años, dentro de políticas inclusivas, redistributivas y de sostenibilidad vinculadas al espacio social europeo.

La Iglesia ¿puede o no ser agente de bienestar? Existen teorías políticas donde no se contempla. La cuestión no es evitarla, sino cómo situarla. El principio de laicidad es el eje. Dios y el César tienen su propia idiosincrasia y espacio. Recordemos la fórmula de Lamennais: «Iglesia Libre-Estado Libre y regidos ambos por la esfe- 
ra superior del derecho». Iglesia y Estado son instituciones llamadas a complementarse, de manera análoga a como puede ser con el Mercado. Y la praxis política en los diferentes Estados así lo viene demostrando. ¿Qué son las Iglesias? Y mejor aún: ¿Cómo deben ser ubicadas dentro de la estructura de los Estados?

La Iglesia, puertas adentro, resulta una cuestión privada que atañe a las conciencias de los creyentes. Los niveles de bienestar que cada una de las confesiones proporcione remiten a esa sutil dimensión de la religatio, respuesta al misterio, conexión con un más allá. Pero, es en el más acá donde centramos el contenido de las políticas públicas. Si, efectivamente, en la medida que las iglesias contemplen una dimensión fraternal, pueden interesar en el terreno de las políticas sociales. Hay una pregunta definitoria: ¿sólo para sus fieles? En ese caso hará su función social, pero no como agente de bienestar, dentro del espacio público que remite a la ciudadanía al completo. El calificativo será adecuado en cuanto efectúe una acción social inclusiva, sin excluir a nadie por raza, sexo, religión, y, más aún, sin hacer proselitismo.

Cáritas, actuando desde la sociedad civil y para la sociedad civil, ha sabido cruzar bien ese umbral, posicionándose dentro del Estado social y democrático de derecho. Los informes FOESSA y su página web está bien que se conozcan desde el primer curso.

La sociedad civil es un estrato significativo para fundamentar las políticas sociales. Ya desde mediados del siglo XIX, viene recogiendo dos dimensiones: ser sujeto y objeto de los derechos formalmente reconocidos, y ser agente libre y responsable en la detección y respuesta a problemas planteados en la ciudadanía. Muchas de las políticas o intervenciones han tenido su origen ella, en el pasado, y en el presente su libre movimiento da forma a la democracia. El Estado, a través de la sociedad civil, viene asegurando muchas atenciones especializadas que han conformado y extendido los derechos sociales, favoreciendo la inclusión y la autonomía personal.

El tercer sector tiene su identidad en las organizaciones no gubernamentales y el trabajo vo- luntario. El Código ético del voluntariado del año 2000 ayuda a definir el término voluntariado. Se pueden descubrir sus principios e indagar sobre su radio de acción, límites y posibilidades dentro de las esferas del bienestar. Conocer la página de la Plataforma del Voluntariado de España es un recurso imprescindible. Es oportuno llamar la atención sobre sus publicaciones.

Hagamos notar que la generosidad del voluntariado tiene un límite y no debe suplir los déficits del Estado ni del Mercado. Un autor que sugerir puede ser Víctor Renes, ayudó a centrar en sus inicios la nueva concepción del voluntariado para un Estado social y democrático, y sigue calibrando cómo debe situarse en el nuevo escenario que arroja la crisis (Renes, 2012). Joaquín García Roca (1996), a comienzos de los noventa, supo romper con lastres benéfico-asistenciales que todavía pesaban y preguntarse cómo articular esta nueva lógica en las relaciones dentro del Estado. Así, salvando valores humanistas, dejó planteados tres niveles sugerentes para centrar ideas y suscitar debate y reflexiones con los estudiantes (García Roca, 1996):

- Estructuras solidarias en las manifestaciones del Estado que hagan viable la justicia.

- Humanizar los procedimientos en la Empresa-Mercado haciendo posible la equidad.

- Ayuda recíproca dentro de los Mundos Vitales que generen empatía (comprensión-pasión).

Entre los cambios sustanciales que compete afrontar al tercer sector está el retroceso del valor del trabajo para la identificación personal y la cohesión social. Y en medio de ello está la entidad del voluntariado manteniendo ese objetivo final: salvar la autoestima de las personas y crear «bienes relacionales» que a todos benefician. Es interesante este sentido formulado ya en años previos a la crisis. Por ejemplo (García Roca, 2004, pp. 60-64). Y como deberá sostenerse la brújula entre lo público y lo privado en los próximos años ${ }^{2}$. Insistamos que la buena disposición del voluntariado no puede desnaturalizarse como reparadores gratuitos de fracturas y ca-

2 Plataforma del voluntariado de España-Observatorio del voluntariado, Profundizar en el voluntariado. Los retos hasta 2020. Año europeo del Voluntariado 2011 (pp. 56- 58), sobre reconfiguración del espacio público y privado. Y también (pp. 59-61) plantea relaciones, limites e interferencias entre voluntariado-relaciones laborales-trabajo remunerado. 
rencias provocadas por medidas políticas antisociales.

La Plataforma de Ong de Acción Social es otro recurso igualmente asequible en la red, e imprescindible que sea conocido cuanto antes. Ayuda a comprender que la sociedad civil viene estructurándose y abriendo su campo de atención, dando respuesta a muchos problemas de autonomía personal e integración social. A partir de ella podemos ayudar a comprender otros términos como pudiera ser, el Pluralismo del bienestar.

A la altura de 2007, cuando se celebró el IV Foro del Tercer Sector, convocado desde la Fundación Luis Vives, nuestro sistema de bienestar estaba alcanzando unas expectativas bastante esperanzadoras. Una referencia que funciona bien en clase, para centrar de manera rápida y expresiva, suscitar el interés y continuar indagando sobre las posibilidades del tercer sector, es la ponencia marco de Rafael Aliena (2008). Sintetizaba tres niveles donde percute el voluntariado:

- Providente: mejora la vida ciudadana, resuelve problemas.

- Instituidor de lo social: promueve, consolida vínculos familiares y sociales; protege tradiciones, recuerdos, experiencias comunitarias.

- Actor político: interviene en la polis como provisor de recursos, debe participar en la esfera pública o presionar buscando mejoras.

El tercer sector, en definitiva, ha venido contribuyendo a estructurar la sociedad civil de una manera democrática, participativa y solidaria. Tiene sus grandezas y sus limitaciones. Ya hace años que Gregorio Rodríguez Cabrero alertó sobre que el Estado de bienestar, que debería operar desde el centro, se estuviese desplazando hacia la periferia.

b) La protección dentro de un sistema democrático y social, y su diferencia con otros tiempos históricos u otras tipologías de Estado

Las políticas sociales tienen hoy su sentido, proporcionando medios de vida, trabajo, bienestar y cobertura social a todas las personas que conviven dentro de un mismo Estado. Y, sin embargo, será útil tomar en consideración ciertos conceptos que tienen que ver con la beneficencia y la asistencia. ¿Por qué incluir en nuestra selección dos términos, uno anacrónico y otro en retroceso? Es muy necesario limar y matizar bien aquello que forma parte de mentalidades previas y fruto de sistemas política y económicamente diferentes, dejando bien centrado que el sentido que debe orientar a las políticas sociales de un Estado social y democrático de derecho, es otro.

No es preciso remontarse a la Edad Media como origen de medidas que puedan encontrarse hoy. Está bien tener una cultura general y saber establecer analogías, pero es necesario tener bien claro que nuestro marco sistémico de relaciones: político, económico, jurídico y de valores es muy diferente. Hoy estamos hablando de políticas respecto a la ciudadanía, no a los siervos ni a los pobres de antaño. Tampoco tiene nada que ver con ciertas políticas en pleno siglo XIX, donde todavía no estaba definida la responsabilidad de los Estados en la redistribución de las riquezas y su obligación para garantizar el bienestar general de la ciudadanía. La obligación hoy está en mejorar los medios para la inclusión $\mathrm{y}$ entonces bastaba con mantener a cada cual en su lugar de origen.

Los historiadores saben manejar bien tales relaciones sistémicas en cada una de las épocas, pero quienes no tienen tal formación, la tendencia a imaginar un proceso evolutivo les puede llevar a adquirir imágenes distorsionadas.

La beneficencia va vinculada a una concepción cerrada y estática de las relaciones en sociedad. Corresponde con épocas donde estaba aceptada la división por estamentos y más tarde por clases sociales. Tal concepción está referida a personas cuyo vínculo con el sistema era estar permanentemente en los márgenes. Tampoco existía el concepto de derecho a los medios para la inclusión, sino tan solo al paliativo, a la subsistencia, a suavizar las duras condiciones de vida. Aquella forma de control social y saneamiento de las ciudades hoy tropieza con otros valores $\mathrm{y}$ una sistematización diferente de los principios políticos.

Los términos: asistencialismo, en sentido de prestaciones de mínimos; paternalismo, como forma de ayuda manteniendo la minoría de edad del asistido; o graciabilidad, que supone la ausencia del derecho y la existencia aleatoria del recurso, son ajenos a la filosofia política que sustenta el Estado social de derecho y marca rupturas radicales producidas a la muerte del general Franco. Es preciso fundamental bien claras tales ideas. 
Las concesiones por gracia carecen de lugar si el ámbito de los derechos sociales está bien perfilado. El derecho sustituye a la arbitrariedad, consolida y regulariza una prestación, reclamable si no llega a implementarse. El Estado queda así obligado a arbitrar medios y medidas para consolidar estructuras y niveles de bienestar. Adquiere un compromiso ante la ciudadanía. Los resabios paternalistas que generan sumisiones y agradecimientos, fuera de normas objetivas de convivencia, no deben persistir en un Estado social.

Una manera rápida y evidente para centrar y asimilar tales conceptos es recurrir a «la construcción histórica de la profesión», presentada por Patrocinio de las Heras en el II Foro de Trabajo Social que tuvo lugar en el año 2000. Fue precisamente por la batalla dada por la Federación Española de Asistentes Sociales, como logró quitarse, la palabra beneficencia de la Constitución española de 1978, que se había filtrado entre sus artículos. Había sido aprobada por el Parlamento y hubo de rectificase en el Senado. Todo un indicador de un estado de la cuestión y de lo lejos que estaban los pobres, por entonces, de la entidad de ciudadanía. La razón era muy clara y jurídicamente consistente: un Estado social y democrático de derecho no puede institucionalizar «dos categorías de ciudadanos, los de los derechos sociales y los de beneficencia pública», además de otros matices descubribles a la vista de este texto (De las Heras, 2000).

Entrar en el concepto de pobreza deberá hacerse, por lo tanto, por el centro del sistema y su responsabilidad en la inclusión de la ciudadanía. Es otro término del que persisten, en el imaginario colectivo, pátinas estáticas y fatalistas propias de tiempos pasados. Es obligado, por lo tanto, trabajar bien los matices desde la nueva perspectiva que deberán adquirir nuestros estudiantes. $\mathrm{La}$ Fundación Luis Vives publicó hace años un folletito de divulgación que sigue siendo un buen material didáctico para el primer un contacto. Esas Claves sobre pobreza y Exclusión (2008) ponen de relieve las dimensiones desde las que se produce o no la integración de las personas y de los colectivos, dentro del esquema que se debe interiorizar. A partir de 2008, ha cobrando forma el concepto de nuevos pobres, vinculado a personas que, de la noche a la mañana, reunieron por sorpresa indicadores de vulnerabilidad. Y dentro de esta última crisis, ya se perfilan los indicadores de pobreza en los trabajadores precarios.
El término exclusión social está ciertamente en consonancia con las políticas que debemos familiarizarnos. El concepto refleja una nueva filosofía política de fondo: ¿Quién es el culpable de la desgracia? ¿El individuo o el sistema que no le ha proporcionado los medios? Efectivamente es el sistema quien excluye, desde dónde se está negando la cabida. Es este ángulo en donde se ha de fijar la atención. La exclusión debe ser entendida desde una concepción integral y multidimensional. Hemos de hacer descubrir cómo supone la ruptura de nexos, en los distintos planos de integración dentro del Estado. Es decir respecto al empleo, la protección social, la participación política, garantías jurídicas, o la familia y redes sociales. En suma, las esferas por donde circula la riqueza, las oportunidades, el bienestar.

Inclusión social sería el mismo término visto desde el lado opuesto. Cabe también recrear con él la imaginación de los estudiantes. Hemos de recordar que estos términos construidos por la sociología, en nuestro caso, deben orientarse a buscar solución mediante políticas públicas. Puede ser también una ocasión para introducir el concepto de últimas redes o mallas de seguridad, sabiendo que son prestaciones de mínimos, propias de situaciones de emergencia (Moreno, 2000), y que solamente contribuyen a la inclusión social si existen otros recursos y política sociales bien desarrollados. Son las últimas, no las primeras ni mucho menos las únicas.

El término cohesión social requiere además de comprender el sentido de las políticas redistributivas en los diferentes sistemas de bienestar, el de la interacción entre los diferentes grupos, etnias, comunidades y sectores sociales. Implica tanto a las políticas públicas como a las disposiciones ciudadanas.

\section{c) La identidad y dignidad de toda persona} humana, principio y fin de la dimensión social El concepto dignidad humana no debería faltar en nuestro diccionario. Tratar con personas, intervenir con ellas, con familias, grupos, etc., es el medio laboral donde transcurrirá la actividad de quienes estamos preparando. Muchas ideas o definiciones pueden aparecer buscando de qué se trata y se presta muy bien a emitir reflexiones y opiniones, generando debate y enriqueciendo puntos de vista. Es importante dejar claro este término y a este respecto no he encontrado, por 
el momento, referente de partida más directo, concreto, y expresivo que el imperativo kantiano: «Obra de tal modo que uses la humanidad, tanto en tu persona como en la persona de cualquier otro, siempre como un fin al mismo tiempo y nunca solamente como un medio».

$\mathrm{Y}$ es que si aceptamos y comprendemos, obrando en consecuencia, que cada cual se pertenece a sí mismo dejamos el espacio de respeto y autonomía necesario para la vida. No olvidemos que nuestro sistema está basado en las libertades y nada más contrario e inconsecuente con tal concepción que instrumentalizar, cosificar, abusar de nuestros semejantes. ¿Libertades para unos que dan lugar a la sumisión y la esclavitud para otros? Muchos argumentos, intervenciones, justificaciones a los recortes en gasto social o a ciertas inversiones financieras, solo tienen sentido desde premisas donde está implícita la cosificación de las personas.

Teniendo por referente la dignidad de las personas viene rodado cómo situarse ante cualquier tipo de diferencias: género, raza, construcciones culturales, y recordemos también las discapacidades. Entender la discapacidad por el vector de la «diversidad humana» es uno de los avances más significativos que hemos tenido en estos últimos años.

Gregorio Peces-Barba es una figura que no debemos olvidar. Su magisterio y compromiso con los valores humanos ha dejado huella dentro de la filosofía del derecho, así como en la construcción y sostenimiento del Estado social y democrático, a fin de cuentas uno de los padres de nuestra Constitución. Entre los diferentes foros y publicaciones donde elegir pedagógicamente, tenemos una de sus últimas intervenciones en un Congreso convocado por la Universidad de Valladolid, con motivo del centenario de la muerte de Cristóbal Colón. La publicación resultante interesa en general por la pluralidad de aspectos y puntos de vista con los que se abordan los derechos humanos, entendidos dentro del sistema político. Expresaré a continuación alguna de las ideas que forman parte del legado intelectual de Peces-Barba y dejó escritas aquí:

El sentido de dignidad humana, formado en el tránsito a la modernidad. sitúa el concepto en el fundamento de los Estados contemporáneos. El universo jerárquico medieval privaba de dignidad a los inferiores, y desde aquel marco teocéntrico todo lo más que pudo llegar San Agustín es a que entendiese derivada de la luz de Dios. La revolución que apunta con el Renacimiento era radical. El ser humano en el centro del sistema y unido a la laicidad. La dignidad arranca, a partir de ahora, del propio individuo, se presta a la autonomía moral, e impulsa el desarrollo individual de la condición humana. Y así la dignidad de las personas está en el fundamento de la ética pública y de ella emanan los valores y derechos que sostienen la democracia. Tiene, por lo tanto, un «puesto prepolítico y prejurídico»; interpretemos que deberá ser piedra angular en ambas esferas (Peces-Barba, 2007).

Los derechos que pueden ser reconocidos es una dimensión atractiva para incidir en ella. La pregunta inicial es evidente ¿Por qué razón somos sujeto de derechos? La pregunta sigue en pie: ¿Cuál puede ser esa dimensión desde la que objetivar y fundamentar derechos con un sentido universal? Por más vueltas que le demos, solo una cosa une a todo el mundo y es el pertenecer a la misma especie: la humana. No todo el mundo percibe con igual intensidad que todos formamos parte de tal entidad, así que no está de más racionalizarlo.

Entre los autores a quienes recurrir, fue claro y meridiano Pufendorf cuando, a la altura de 1672, explicitó: «La persona humana es sujeto de derechos por su propia Naturaleza». Y por si no queda claro del todo, completaba: «La persona moral es la que constituye las sociedades»».

A partir de tomar conciencia de nuestra dignidad y de que, puestos en sociedad, podemos reconocer y disfrutar de derechos, es posible matizar el concepto. Los derechos pueden vincularse a la dimensión personal, social, laboral o política. Llevar la reflexión sobre estos aspectos suele resultar estimulante a la imaginación y a la inteligencia; suscita debates interesantes. La concepción de ciudadanía propia del Estado social y democrático implica desarrollar políticas públicas que atañen a las diferentes entidades adoptadas dentro del sistema: individuo, creyente (si es el caso), trabajador y ciudadano.

Una vez formulados en las leyes, los derechos cobran su contenido a través de los sistemas de bienestar, las diferentes políticas públicas y los programas específicamente diseñados para favorecer la inclusión e integración.

Los derechos sociales se han ampliado en los últimos años. Incluso vienen matizando especificidades tratando de contrarrestar situaciones 
de vulnerabilidad vinculadas a la edad, al género, a limitaciones de la autonomía personal, a las migraciones.

El discurrir de los derechos y las libertades es, en definitiva, consustancial con las políticas sociales. Desde aquí puede derivarse hacia conceptos como: educación, sanidad, vivienda o diferentes servicios y prestaciones que remiten no solo al derecho en sí mismo sino de nuevo a la función del Estado y al juego entre los agentes de bienestar para garantizarlo e implementarlo adecuadamente. El Barómetro social de España, del Colectivo IOE, es otro recurso interesante dentro del espacio virtual. Ayuda, desde el primer curso, llevar la atención sobre el abanico de las políticas sociales que expresamente contempla, sus potencialidades y sus riesgos dentro de la arquitectura del Estado.

\section{Referencias bibliográficas}

Aliena, R. (coord.) (2008). Los equilibrios del Tercer Sector. Una filosofía del pluralismo de funciones. IV Foro del Tercer Sector. Fundación Luis Vives. Recuperado de: http://www.luisvivesces. org/publicaciones/

Ashford, D. E. (1989). La aparición de los Estados de Bienestar, Madrid: Ministerio de Trabajo y Seguridad Social.

Beveridge. (1988), Pleno empleo en una sociedad libre. Madrid: Ministerio de Trabajo y Seguridad Social.

Colectivo IOE. Barómetro social de España. Recuperado de: http://barometrosocial.es/

De las Heras, P. (2000). La construcción histórica de una profesión. II Foro de Trabajo Social, Pasado, Presente y Futuro del Trabajo Social. Madrid: Universidad Pontificia de Comillas.

Esping-Andersen, G. (1993). Los tres mundos del Estado de Bienestar. Valencia: Editions Alfons i Magnanim.

Ferrera, M. (1995). Los Estados del Bienestar del Sur en la Europa social. En S. Sarasa y 1. Moreno (eds.), El Estado del Bienestar en la Europa del Sur. Madrid: CSIC.

FOESSA. Disponible en: http://www.foessa.es/publicaciones_periodicas.aspx

Fundación Luis Vives. (2008). Claves sobre la pobreza y la exclusión social en España. Recuperado de: www.fundacionluisvives.org

García Roca, J. (1994). Solidaridad y Voluntariado. Santander: Sal Terrae.

García Roca, J. (2004). Políticas y programas de participación social. Madrid: Síntesis.

Marshall, T.H. y Bottomore, T. (1998). Ciudadanía y clase social. Madrid: Alianza.

Martínez de Pisón, J. (1998). Políticas de Bienestar. Un estudio sobre los derechos sociales. Madrid: Tecnos- Universidad de la Rioja.

Moreno, L. (2000). Ciudadanos precarios. Barcelona: Ariel.

Peces-Barba, G. (2007). La dignidad humana. En R. de Asís, D. Bondia y E. Maza (coords.), Los desafios de los derechos humanos hoy (pp.155-170). Madrid: Dykinson S.L.

Picó, J. (1996). Modelos sobre el Estado de Bienestar. En R.Casilda Bejar y J.M.Tortosa (edits.), Pros y contras del Estado del Bienestar (pp 37 - 57). Madrid: Tecnos.

Plataforma de las ONG. Disponible en: http://www.plataformaong.org/

Plataforma del Tercer Sector. Disponible en: http://www.plataformatercersector.es/

Plataforma del voluntariado de España - Observatorio del voluntariado. (2011), Profundizar en el voluntariado. Los retos hasta 2020. Recuperado de: http://www.plataformavoluntariado.org/publicaciones.php.

Ramos Gorostiza, J.L. (s.f). Beatrice Webb y el Socialismo Fabiano. Recuperado de: http://eprints. ucm.es/6735/1/0113.pdf

Raya Díez, E. (2002). Políticas sociales y de ciudadanía. Vitoria-Gasteiz: Servicio Central de Publicaciones del Gobierno Vasco.

Renes, V. (2012). El papel del voluntariado en el siglo XXI. Congreso de Voluntariado, Bilbao 27-29 de Noviembre. Recuperado de: http:/www.eapn.es/ARCHIVO/documentos/recursos/5/Ponenciacongresovdo.pdf

Titmusss, R. (1981). Política social. Barcelona: Ariel. 


\section{Manuales para manejar}

Aguilar Idañez Ma José (2013). Trabajo social. Conceptos y metodología. Madrid: Consejo General del Trabajo Social.

Alemán Bracho, Carmen (coord..) (2009). Politicas Sociales. Madrid: Civitas - Thompson.

Alemán Bracho, Carmen y Garcés Ferrer, Jorge (coords.) (1997). Política Social. Madrid: McGrawHill.

Álvarez Uría, Fernando (2004). Sociología, capitalismo y democracia. Madrid: Morata.

García Fernández, Tomás, de la Fuente, Yolanda (2009). Política Social y Trabajo Social. Madrid: Alianza.

Giner, Salvador (2008). Historia del pensamiento social. (14a ed.). Barcelona: Ariel.

Izquierdo, Juan de Dios, Torres, Rubén y Martínez, Laura (2011). Estado de Bienestar y Trabajo social. Madrid: UNED Ediciones Académicas.

Montagut, Teresa (2008). Política Social. Una introducción. ( $3^{\text {a }}$ edición actualizada). Barcelona: Ariel.

Noguera Fernández, Albert, Guamán Hernández, Adoración (dirs.)(2014). Lecciones sobre Estado Social y Derechos Sociales. Valencia:Tirant lo Blanc.

Roldán, Elena, García-Giráldez, Teresa (2006). Políticas de Servicios Sociales. Madrid: Síntesis.

Roldán-García, Elena, García-Giráldez, Teresa y Nogués-Sáez, Luis (2013). Los servicios sociales en España. Madrid: Síntesis.

\section{Diccionarios}

Ariño, Antonio (ed.) (2003). Diccionario de la solidaridad. Cuadernos de la Solidaridad, $\mathrm{n}^{\mathrm{o}} 2$. Valencia: Tirant lo Blanc. [Por ejemplo: Voz «Estado de Bienestar» de Gregorio Rodríguez Cabrero, deja ideas claras en la misma línea de lo que debemos fundamentar en el primer curso].

Uña Juárez, Octavio y Hernández Sánchez, Alfredo (2004). Diccionario de Sociología. Madrid: ESIC.[ Por ejemplo: Voz «Servicios Sociales» de Elena Roldán]. 